ASM Sc. J., 13, 2020

https://doi.org/10.32802/asmscj.2020.sm26(2.10)

\title{
Effect of Annealing Temperature on Electrical Properties of Hybrid ZnO/PTAA based Heterojunction Diode
}

\author{
Abdul Ismail Abdul Rani, Ghosh Bablu Kumar'1, Khairul Anuar Mohamad², Chee Fuei Pien³, Mohd \\ Shahril Osman ${ }^{4}$ Ismail Saad ${ }^{1}$, Norjannah Yusop³ \\ ${ }^{1}$ Electrical and Electronic Engineering, Faculty of Engineering, Universiti Malaysia Sabah, Jalan \\ UMS, 88400 Kota Kinabalu, Sabah, Malaysia. \\ ${ }^{2}$ Faculty of Electrical and Electronic Engineering, \\ Universiti Tun Hussein Onn Malaysia 86400 Parit Raja, Batu Pahat, Johor, Malaysia \\ ${ }^{3}$ Faculty of Science and Natural Resources, \\ Universiti Malaysia Sabah, Jalan UMS, 88400 Kota Kinabalu, Sabah, Malaysia \\ ${ }^{4}$ Electrical and Electronic Engineering Program, School of Engineering and Technology, University \\ College of Technology Sarawak, Sibu, Malaysia
}

\begin{abstract}
A hybrid type heterojunction diode based on Zinc Oxide ( $\mathrm{ZnO})$ and Poly(triarylamine)(PTAA) thin films is fabricated using radio frequency and spin coating method. These are conducted in ambient condition. This research is done to investigate the effects of temperature on Schottky properties of ZnO/PTAA diode. PTAA is chemically dissolved in chloroform solution and deposited onto $\mathrm{ZnO}$ thin film at different spin rate of $1000 \mathrm{RPM}$ and $2000 \mathrm{RPM}$. The fabricated diode is then annealed for 20 mins at a temperature ranging from $100{ }^{\circ} \mathrm{C}$ to $150{ }^{\circ} \mathrm{C}$ and surface morphological of fabricated diodes is observed using advance material microscope (HIROX). Investigation of current-voltage (I-V) is carried out in various bias voltage from $-4.0 \mathrm{~V}$ to $4.0 \mathrm{~V}$ using Keithley 4-point prob. Investigation revealed that, diode show rectifying behaviour towards the increasing in annealing temperature. The highest ideality factor obtain is 1.62 at $120^{\circ} \mathrm{C}$ for $1000 \mathrm{RPM}$ with barrier height of $0.745 \mathrm{eV}$ and series resistance of $2.645 \mathrm{~K} \Omega$. The barrier height of diodes increases gradually with increasing in temperature while ideality factor decreases. Meanwhile, series resistance decreases significantly over increasing temperature from $4.28 \mathrm{~K} \Omega$ to $0.412 \mathrm{~K} \Omega$ for 1000 RPM and $4.166 \mathrm{~K} \Omega$ to $0.063 \mathrm{~K} \Omega$ for $2000 \mathrm{RPM}$. It clearly reveals that the temperature is highly correlated with the ideality factor of the device thus effecting the barrier height and series resistance in the device.
\end{abstract}

Keywords: Zinc Oxide, Poly(triarylamine), current-voltage (I-V), ideality factor, barrier height

\section{INTRODUCTION}

In recent years, combination of conjugated organicinorganic based heterojunction device have attracted most of attention towards research of this hybrid technology as it allows the development of microelectronics technology and potentially at low fabrication cost (Faltakh et al. 2015; Kim et al. 2011). This particular hybrid device combines the advantages of both organic and inorganic material thus increases its efficiencies at the same time reducing the drawbacks (Banerjee \& Chattopadhyay, 2018). Several advantages of this hybrid-based device includes requirement of low fabrication temperature, high solubility in solvent and also stable in ambient condition (Miandal, Mohamad, \& Alias, 2016; Miandal et al. 2017). In this research, organic-inorganic material used are Polytriarylamine (PTAA) and Zinc Oxide ( $\mathrm{ZnO})$. $\mathrm{ZnO}$ is one of the most capable inorganic materials as it possesses wide band gap of $3.3 \mathrm{eV}$ and large binding energy $60 \mathrm{MeV}$

*Corresponding author's e-mail: abdismail.ar@gmail.com 
(Bensmaine \& Benyoucef, 2014; Özgür et. al., 2005; Sanjeev \& Kekuda, 2015). As for PTAA, this conjugated polymer amorphous structure has allow the movement of electron to pass it with hole mobility of $10^{-3}$ up to $10^{-2}$ $\mathrm{cm}^{2} / \mathrm{V}^{-1} \mathrm{~s}^{-1}$ (Miandal et. al., 2016). Many researchers have investigated regarding structural, morphological and optical combination of these organic-inorganic material to improve the device performances (Bonea, Bonfert \& Svasta, 2011; Castro-Carranza et al. 2012; Cho et al. 2012; Sendner, Trollmann \& Pucci, 2014; Smith et al. 2009; Yadav, Singh \& Tripathi, 2012). Such development is necessary for investigation of ZnO/PTAA of Schottky diodes-based heterojunction device. This work focuses on $\mathrm{I}-\mathrm{V}$ characteristic of the hybrid diode by thermionic emission (TE) model at different temperatures ranging from $100{ }^{\circ} \mathrm{C}$ to $150^{\circ} \mathrm{C}$.

\section{MATERIALS AND METHODS}

$\mathrm{ZnO}$ /PTAA films is deposited onto ITO by using two different methods which are radio frequency (RF) sputtering and spin coating method. The RF power is kept at $100 \mathrm{~W}$ with the mixture of Argon ( $\mathrm{Ar})$ and Nitorgen $\left(\mathrm{N}_{2}\right)$ gas at flow rate of $8 \mathrm{sccm}$ in room temperature level. $\mathrm{ZnO}$ thin film thickness is approximately $\sim 300 \mathrm{~nm}$ after deposition for 40 minutes. For a better wurtzite structure of $\mathrm{ZnO}$, the film is annealed at $400{ }^{\circ} \mathrm{C}$ for an hour (Sanjeev \& Kekuda, 2015). As for organic film, PTAA (Lumtec) is firstly dissolved and soaked in chloroform for 12 hours to obtain $1 \%$ wt polymer mixture. PTAA is deposited onto the $\mathrm{ZnO}$ layer at different spin coating speed of 1000 RPM and 2000 RPM. Approximately, thickness of PTAA obtained are $\sim 100 \mathrm{~nm}$ and $\sim 60 \mathrm{~nm}$ for 1000 and 2000 RPM respectively. The fabricated thin film is further synthesized by annealing the thin film at different temperature ranging from $100{ }^{\circ} \mathrm{C}$ to 150 ${ }^{\circ} \mathrm{C}$ for 20 minutes. The thickness of film is evaluated and obtained by using Nanomap LS500 Profilometer respectively. The fabrication of device continues by depositing the $\mathrm{Al}$ electrode through designated mask of 0.4 $\mathrm{cm}$ in diameter on top of PTAA layer by using DC sputtering method. Aluminium is chosen as the electrode because $\mathrm{Al}$ has low work function thus increases the injection of electron towards the active layer (Mohamad et. al., 2017). The thickness of $\mathrm{Al}$ electrode deposited onto the hybrid thin film layer is approximately $\sim 100 \mathrm{~nm}$. Surface morphological and $\mathrm{I}-\mathrm{V}$ measurement are done at room temperature using
Advance material microscope (HIROX) and Keithley 2400 2-point probe in ambient condition from - $4 \mathrm{~V}$ to $4 \mathrm{~V}$ forward and reverse bias condition. The morphological and electrical $\mathrm{I}-\mathrm{V}$ characteristic obtained are tabulated and analysed.

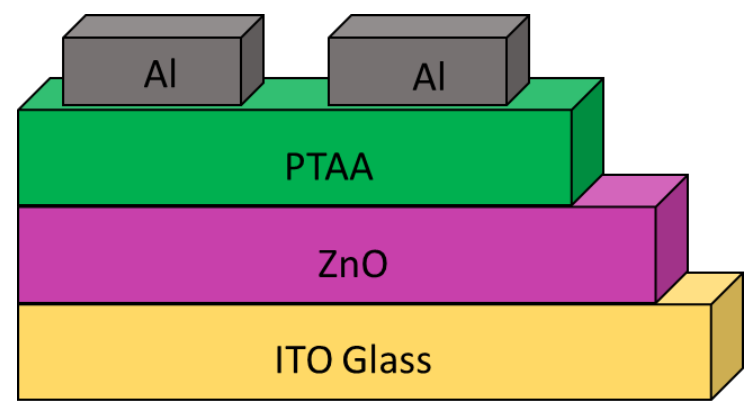

Figure 1. ITO/ZnO-PTAA/Al hybrid-based heterojunction layer structure

\section{RESULTS AND DISCUSSIONS}

\section{A. Surface Morphology}

Surface morphology of thin films are studied using advanced material microscope, KH-8700 model (HIROX). HIROX images of $\mathrm{ZnO}$ thin film and PTAA film deposited at 1000 RPM and 2000 RPM is as shown in the Figure 2 respectively. As the speed rate of the spin coating increases the PTAA layer is deposited uniformly onto the $\mathrm{ZnO}$ layer (Miandal et. al., 2017). The centripetal force combined with the surface tension of the liquid PTAA pulls the coating into an even covering, at the same time it evaporates, leaving the desirable thin film onto the $\mathrm{ZnO}$ layer for a smoother surface (Miandal et. al., 2017). A more saturated form of PTAA cluster can be observed at 1000 RPM compared to 2000 RPM as the thickness of thin film layer is higher. As for 2000 RPM, a smoother layer is formed and evenly distributed on the $\mathrm{ZnO}$ layer. Distribution of PTAA layer onto the $\mathrm{ZnO}$ affect the ability of the fabricated diode to facilitate the movement of charges at the interface between inorganic-organic. Therefore, with the aids of annealing temperature, the interface between the 2 layers can merge optimally and increase the transfer of electron through the interface (Esopi et al. 2018; Miandal et. al., 2016). 

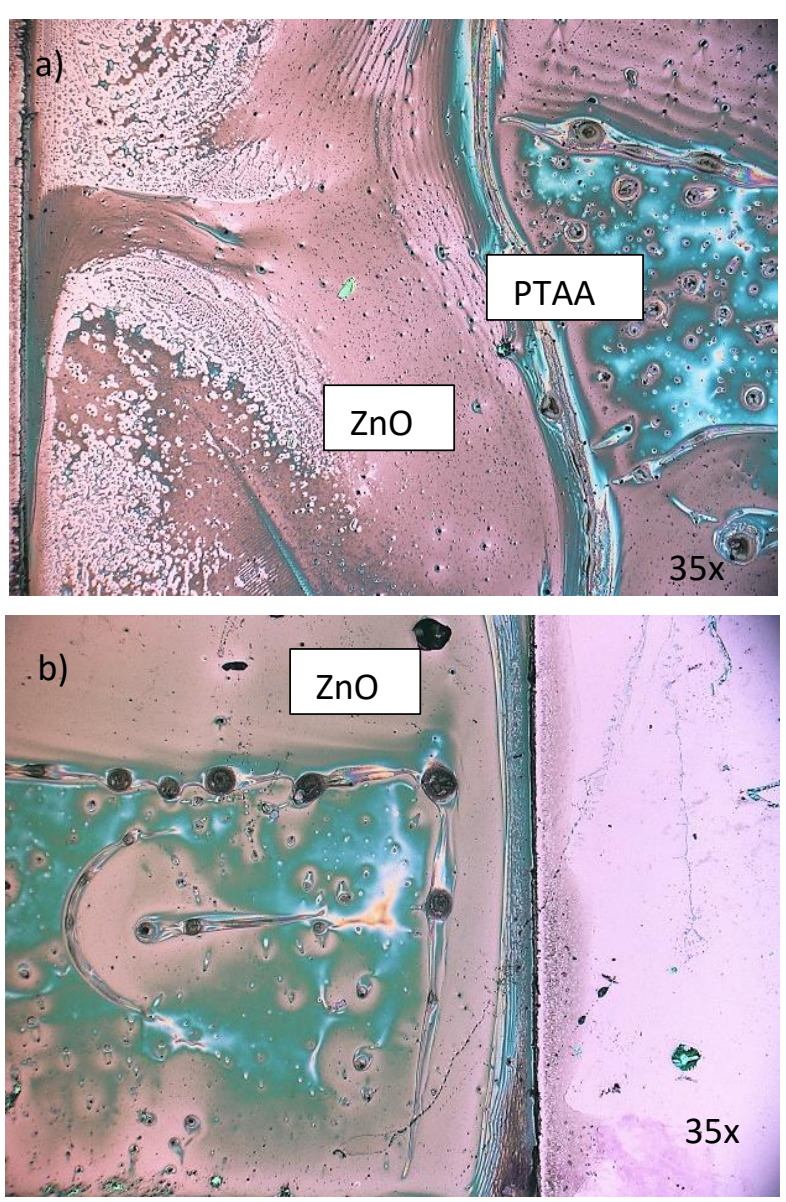

Figure 2. Surface morphology of fabricated diode, $\mathrm{ZnO}$ and PTAA in room temperature condition with a low range lens a) 1000 RPM b) $2000 \mathrm{RPM}$

\section{B. Ideality Factor and Barrier Height Analysis}

Current-voltage (I-V) measurement of ITO/ZnO-PTAA/Al is carried out at room temperature to investigate the electrical properties of the fabricated diode. The electrical characteristic shows good rectifying behaviour and discloses that the fabricated device possesses Schottky properties. In this case, thermionic emission (TE) model is used to extract the electrical parameters and at the same time tabulating the characteristic of the electrical properties (Imer, Tombak \& Korkut, 2016; Kadaoui et al. 2015; Tran Anh Tuan et al. 2015). The rectifying behaviours of $\mathrm{I}-\mathrm{V}$ characteristic of 1000 and 2000 RPM at different temperature are as shown in the Figure 3 .
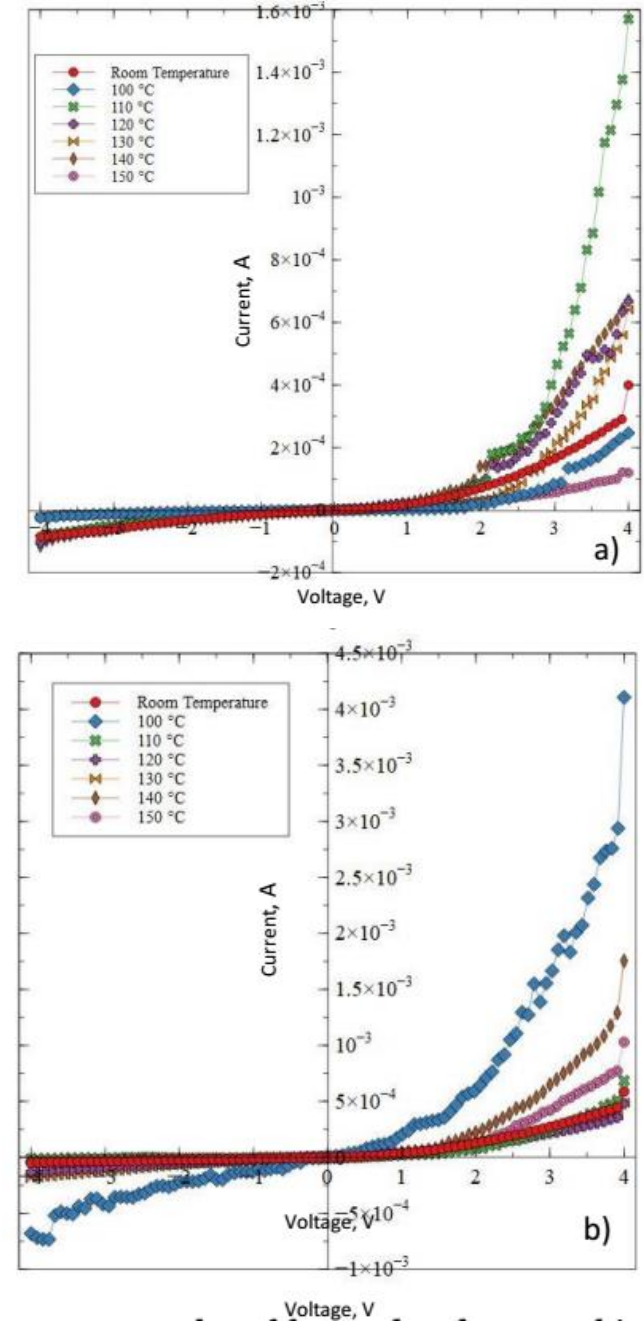

Figure 3. I-V plot of forward and reverse bias at different temperature. a) $1000 \mathrm{RPM} \mathrm{b)} 2000 \mathrm{RPM}$

According to the theory of thermionic emission, the net current can be expressed as (Imer et al. 2016; Tran Anh Tuan et al. 2015),

$$
I=I_{S} \exp \left[\left(\frac{q\left(V-I R_{S}\right)}{n k T}\right)-1\right]
$$

where $I_{S}$ is the saturation current, q is electronic charge, $R_{S}$ is series resistance, $\mathrm{k}$ is the Boltzmann constant and $\mathrm{T}$ is the ambient temperature in Kelvin. The value of $I_{s}$ can be obtain by extrapolating the linear portion of the semi-log plot of I$\mathrm{V}$ characteristic at zero biased voltage and can be expressed as (Barker et al. 1997; Imer et al. 2016; Tran Anh Tuan et al. 2015),

$$
I_{S}=A A^{*} T^{2} \exp \left(-\frac{q \Phi_{B}}{k T}\right)
$$

At this point, $\mathrm{A}$ is the area of contact, $\mathrm{A}^{*}$ is the Richardson constant and lastly $\Phi_{\mathrm{B}}$ is the barrier height between the $\mathrm{ZnO}$ PTAA/Al interface. As for ideality factor, $\mathrm{n}$ and barrier height (BH) $\Phi_{\mathrm{B}}$, the value can be obtained by using these expression (Imer et al. 2016; Lee, Park \& Choi, 2003; Tran Anh Tuan et al. 2015). 


$$
\begin{aligned}
& n=\frac{q}{k T} \frac{d V}{d \ln (I)} \\
& \Phi_{B}=\frac{k T}{q} \ln \frac{A A^{*} T^{2}}{I_{S}}
\end{aligned}
$$

The values of ideality factor and the barrier height between the interface of $\mathrm{ZnO}-\mathrm{PTAA} / \mathrm{Al}$ are determined and tabulated in Table 1.
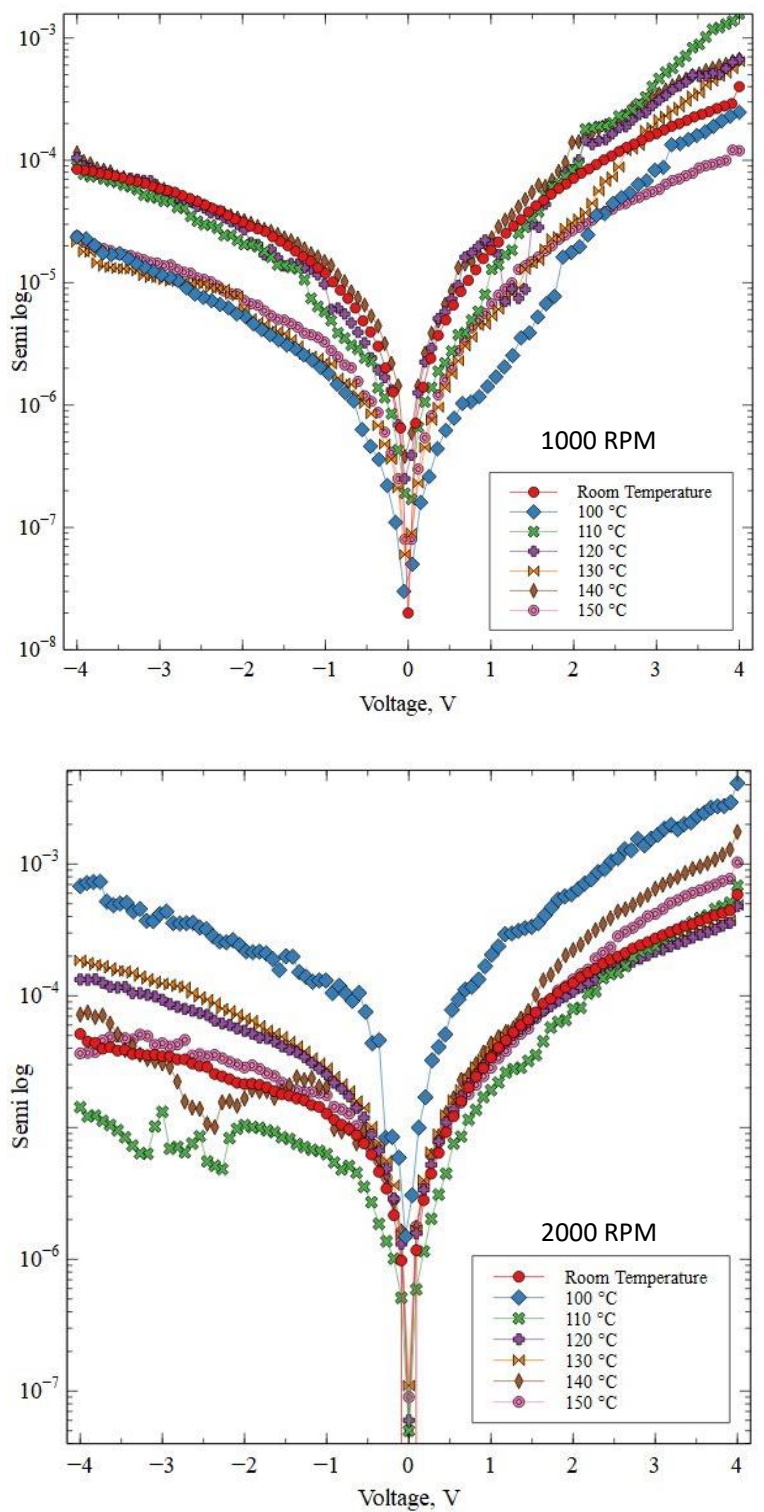

Figure 4. Semilogarithmic I-V plots of 1000 RPM and 2000 RPM under different temperature range

Based on the data obtained, the value of $n$ decreases with the increase in temperature. This is due to the combination of low and high barrier height of the diode in standard TE mode. In the state of room temperature, the electron transport can overcome the barrier height thus provides large value of ideality factor of 19.70 for 1000 RPM and 20.58 for 2000 RPM. For 1000 RPM, it was obtained that at $120{ }^{\circ} \mathrm{C}$, the $n$ value is 1.62 approaching to one which indicates behaviour of an ideal diode. This is due to the good crystallization and amorphous structure of both $\mathrm{ZnO}$ and PTAA during fabrication process. With a good morphological structure, it increases the generation and recombination rates at the interface of the active layer, thus increases its performances (Akkaya et. al., 2014; Shao et al. 2016). Hence, the value of $n$ analysed based on the equation (3) and (4) is in the range of $1.626-20.86$ for 1000 RPM and $13.36-$ 24.83 for 2000 RPM.

Meanwhile, $\mathrm{BH}$ increases with the increasing of temperature. As the temperature increase, more electrons will gain sufficient energy and transcend to a higher barrier thus giving effect to the ideality factor which increases in $\mathrm{BH}$, resulting in a lower value of $n$ (Tran Anh Tuan et al. 2015). According to data tabulated in Table 1, at 1000 RPM the $\Phi_{\mathrm{B}}$ at room temperature is at the lowest with a value of $0.719 \mathrm{eV}$. The BH for 1000 RPM increases insignificantly as the value fluctuates due to the voltage drop at the interfacial layer and surface defect of the device (Kumar, et. al., 2013; Tran Anh Tuan et. al., 2015). For 2000 RPM, BH increases gradually from $0.668 \mathrm{eV}$ at room temperature to $0.777 \mathrm{eV}$ at $150{ }^{\circ} \mathrm{C}$. In consequences with $\mathrm{BH}, R_{s}$ limit the process of conduction thus giving effect towards the value of $n$ and $\mathrm{BH}$ (Dogan \& Elagoz, 2014). At the same time, $R_{s}$ decrease significantly with the increasing of annealing temperature. This occurs due to lower concentration of free carrier at the junction of active layer at low temperature (Dogan \& Elagoz, 2014).

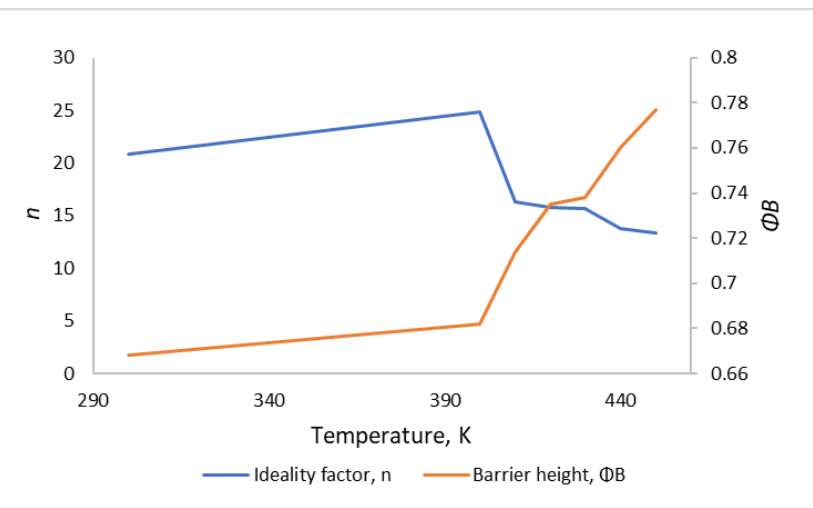

Figure 5. Barrier height and Ideality factor vs. temperature plot at 2000 RPM with different annealing temperature

Table 1. Temperature dependant values determined from forward bias of I-V characteristic of ITO/ZnO-PTAA/Al

\begin{tabular}{|c|c|c|c|c|c|}
\hline RPM & $\begin{array}{c}\text { Temperat } \\
\text { ure } \\
/{ }^{\circ} \mathrm{C}\end{array}$ & $\begin{array}{c}\text { Turn } \\
\text { On } \\
\text { /V }\end{array}$ & $n$ & $\mathrm{R}_{\mathrm{s}} / \Omega$ & $\begin{array}{l}\Phi_{\mathrm{B}} \\
/ \mathrm{eV}\end{array}$ \\
\hline \multirow{2}{*}{$\stackrel{0}{\circ} 0$} & Room & 1.22 & 19.70 & 4280 & 0.719 \\
\hline & 100 & 2.40 & 20.86 & 4129 & 0.792 \\
\hline
\end{tabular}
based device 


\begin{tabular}{|c|c|c|c|c|c|}
\hline \multirow{4}{*}{} & 110 & 2.54 & 14.71 & 2663 & 0.758 \\
\cline { 2 - 6 } & 120 & 2.11 & 1.62 & 2645 & 0.745 \\
\cline { 2 - 6 } & 130 & 2.53 & 18.24 & 1921 & 0.775 \\
\cline { 2 - 6 } & 140 & 1.38 & 15.93 & 728 & 0.724 \\
\cline { 2 - 6 } & 150 & 1.64 & 20.81 & 412 & 0.762 \\
\hline \multirow{4}{*}{$\&$} & Room & 1.02 & 20.85 & 4166 & 0.668 \\
\cline { 2 - 6 } & 100 & 1.63 & 24.83 & 3793 & 0.682 \\
\cline { 2 - 6 } & 110 & 2.17 & 16.28 & 2995 & 0.714 \\
\cline { 2 - 6 } & 120 & 1.75 & 15.81 & 1796 & 0.735 \\
\cline { 2 - 6 } & 130 & 1.38 & 15.67 & 1485 & 0.738 \\
\cline { 2 - 6 } & 140 & 2.13 & 13.79 & 613 & 0.760 \\
\hline
\end{tabular}

\section{ACKNOWLEDGEMENT}

This work is supported by University Malaysia Sabah under UMSGreat Grant (GUGo183) fund and Ministry of Higher Education Fundamental Research Grant Scheme (FRGS) 2016 FRGS/1/2016/STGo2/UMS/02/2. The author is thankful to the Artificial Intelligence Research Unit (AiRU) for providing excellent research environment.

\section{SUMMARY}

ZnO-PTAA diode has been successfully fabricated using two method which are RF sputtering and spin coating method. The fabricated diode shows rectifying behaviour characteristic over increment in temperature. It is reveals that, the best ideality factor obtain is 1.62 at $120{ }^{\circ} \mathrm{C}$ of 1000 RPM. It is also found that, the barrier height rises significantly with the increasing of temperature at the same time the fall for ideality factor of 2000 RPM. The barrier height obtained ranging from $0.719 \mathrm{eV}$ to $0.792 \mathrm{eV}$ for 1000 RPM and $0.668 \mathrm{eV}$ to $0.777 \mathrm{eV}$ for $2000 \mathrm{RPM}$. Meanwhile, the series resistance decreases over increasing in annealing temperature at 1000 and 2000 RPM from $4280 \Omega$ to $412 \Omega$ and from $4166 \Omega$ to $63 \Omega$. However, the value of barrier height, ideality factor and series resistance depend on many affecting factors, which correlate with each other's performance such as morphological orders of crystallinity, voltage drop in the interface layer and free carrier concentration at the active layer. Clearly, the affecting factors must be overcome to get a better result thus increase the performances of the diode. 


\section{REFERENCES}

Akkaya, A., Esmer, L., Kantar, B. B., Çetin, H. \& Ayyildiz, E. 2014, Effect of thermal annealing on electrical and structural properties of $\mathrm{Ni} / \mathrm{Au} / \mathrm{n}-\mathrm{GaN}$ Schottky contacts. Microelectronic Engineering, 130, pp. 6268.

Banerjee, D. \& Chattopadhyay, K. K. 2018, Hybrid Inorganic Organic Perovskites. Perovskite Photovoltaics. Elsevier Inc. pp. 123-162.

Barker, P. S., Monkman, A. P., Petty, M. C. \& Pride, R.1997, Electrical characteristics of a polyaniline/silicon hybrid field-effect transistor gas sensor. IEE Proceedings-Circuits, Devices and Systems, 144(2), pp. 111-116.

Bensmaine, S. \& Benyoucef, B. 2014, Effect of the temperature on $\mathrm{ZnO}$ thin films deposited by r.f. magnetron. Physics Procedia, 55, pp. 144-149.

Bonea, A., Bonfert, D. \& Svasta, P. 2011, Contact Resistance in Polytriarylamine Based Organic Transistors. Proceedings of the 2011 34th International Spring Seminar on Electronics Technology (ISSE). IEEE., pp. 430-435.

Castro-Carranza, A., Nolasco, J. C., Estrada, M., Xu, Y., Benwadih, M. \& Gwoziecki, R. Pallarès, J. 2012, Study of the interface area effect on the density of states in PTAA-Cytop ® OTFTs. 8th International Caribbean Conference on Devices, Circuits and Systems (ICCDCS) . IEEE., pp. 1-3.

Cho, S. Y., Ko, J. M., Jung, J. Y., Lee, J. Y., Choi, D. H. \& Lee, C. 2012, High-performance organic thin film transistors based on inkjet-printed polymer/TIPS pentacene blends. Organic Electronics: Physics, Materials, Applications, 13(8), pp.1329-1339.

Dogan, H. \& Elagoz, S. 2014, Temperature-dependent electrical transport properties of $(\mathrm{Au} / \mathrm{Ni}) / \mathrm{n}-\mathrm{GaN}$ Schottky barrier diodes. Physica E: Low-Dimensional Systems and Nanostructures, 63, pp. 186-192.

Esopi, M. R. 2018, Tuning the spectral response of ultraviolet organic - inorganic hybrid photodetectors via charge trapping and charge collection narrowing. Physical Chemistry Chemical Physics, 20(16), pp. 11273-11284.
Faltakh, H., Mahdouani, M., Hemdana, I., Dkhil, S. Ben, Bourguiga, R. \& Davenas, J. 2015, Extraction of different parameters of hybrid solar cell based on PVK/Silicon nanowires. Superlattices and Microstructures, 79, pp. 166-179.

Imer, A. G., Tombak, A. \& Korkut, A. 2016, Electrical and photoelectrical characteristic investigation of a new generation photodiode based on bromothymol blue dye. Journal of Physics: Conference Series, 707(1).

Kadaoui, M. A., Bouiadjra, W. B., Saidane, A. Belahsene, S. \& Ramdane, A. 2015,. Electrical parameters of $\mathrm{Au} / \mathrm{n}-\mathrm{GaN}$ and $\mathrm{Pt} / \mathrm{n}-\mathrm{GaN}$ Schottky diodes. Superlattices and Microstructures,82, pp. 269-286.

Kim, J. B., Fuentes-Hernandez, C., Hwang, D. K., Potscavage, W. J., Cheun, H. \& Kippelen, B. 2011, Vertically stacked hybrid organic-inorganic complementary inverters with low operating voltage on flexible substrates. Organic Electronics: Physics, Materials, Applications. Organic Electronics, 12(1), pp. 45-50.

Kumar, A., Vinayak, S. \& Singh, R. 2013, Microstructural and temperature dependent electrical characterization of $\mathrm{Ni} / \mathrm{GaN}$ Schottky barrier diodes. Current Applied Physics, 13(6), pp. 11371142.

Lee, Y. S., Park, J. H. \& Choi, J. S. 2003), Electrical characteristics of pentacene-based Schottky diodes. Optical Materials, 21 (1-3), pp. 433-437.

Miandal, K., Mohamad, K. A. \& Alias, A. 2016, Akademia Baru Annealing heat treatment of Poly ( triarylamine ) ( PTAA ) thin films deposited using spin coating Akademia Baru, 1(1), pp. 7-12.

Miandal, K., Tak, H. H., Mohamad, K. A., Chee, F. P. \& Alias, A. 2017, The structural and optical properties of poly(Triarylamine) (PTAA) thin films prepared at different spin rate using spin coating method. Advanced Science Letters, 23(2), pp. 1337-1339. 
Mohamad, K. A., Hoh, H. T., Alias, A., Ghosh, B. K. \& Fukuda, H. 2017, Frequency and voltage dependent electrical responses of poly(triarylamine) thin filmbased organic Schottky diode. EPJ Web of Conferences, 162, pp. 26-29.

Özgür, Ü., Alivov, Y. I., Liu, C., Teke, A., Reshchikov, M. A., Doğan, S., ... Morko, H. 2005, A comprehensive review of $\mathrm{ZnO}$ materials and devices. Journal of Applied Physics, 98(4), 041301.

Sanjeev, S. \& Kekuda, D. 2015, Effect of annealing temperature on the structural and optical properties of zinc oxide $(\mathrm{ZnO})$ thin films prepared by spin coating process. IOP Conference Series: Materials Science and Engineering, 73(1), 012149.

Sendner, M., Trollmann, J. \& Pucci, A. 2014, Dielectric function and degradation process of poly(triarylamine) (PTAA). Organic Electronics: Physics, Materials, Applications, 15(11), pp. 2959-2963.

Shao, H., Fang, J., Wang, H., Dai, L. \& Lin, T. 2016, Polymer-Metal Schottky Contact with Direct-Current Outputs. Advanced Materials, 28(7), pp. 1461-1466.

Smith, J., Hamilton, R., McCulloch, I., Heeney, M., Anthony, J. E., Bradley, D. D. C. \& Anthopoulos, T. D. 2009, High mobility p-channel organic field effect transistors on flexible substrates using a polymersmall molecule blend. Synthetic Metals, 159(21-22), pp. 2365-2367.

Tran Anh Tuan, T., Kuo, D.-H., Li, C.-C. \& Li, G.-Z. 2015, Effect of Temperature Dependence on Electrical Characterization of p-n GaN Diode Fabricated by RF Magnetron Sputtering. Materials Sciences and Applications, 6(6), pp. 809-817.

Yadav, A., Yadav, S., Singh, S. \& Tripathi, N. 2012, Analysis And Parameter Extraction of Organic Transistor At PTAA With Different Organic Materials. International Journal of Scientific \& Technology Research, 1(10), pp. 108-113. 